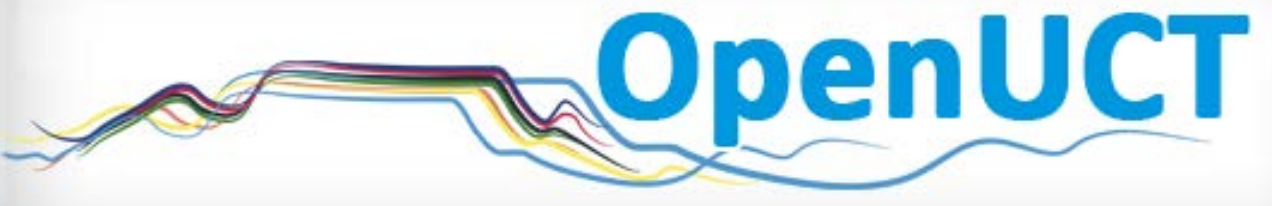

This is the post-print of Luckett, K. 2009. The relationship between knowledge structure and curriculum: a case study in sociology. Studies in Higher Education. 34(4): 441-453. DOI: 10.1080/03075070902772018.

It is made available according to the terms of agreement between the author and the journal, and in accordance with UCT's open access policy available: http://www.openuct.uct.ac.za/sites/default/files/UCTOpenAccessPolicy.pdf, for the purposes of research, teaching and private study. 


\title{
The relationship between knowledge structure and curriculum: a case study in sociology
}

Kathy Luckett*

Centre for Higher Education Development, University of Cape Town, Cape Town, South Africa

\begin{abstract}
This article aims to address a theoretical question, 'what is the relationship between knowledge structure and curriculum structure?', by answering an empirical, context-specific question, 'what drives and legitimates the curriculum in one sociology department?', with an emphasis on surfacing the 'recontextualising rules' at work in this particular institutional context. These questions were explored by conducting a case study in the wake of a departmental review. The conceptual framework for the article is based on Bernstein's sociology of education and on those who have developed his work further. The findings support Bernstein's characterisation of sociology as a discipline with weak external boundaries, a horizontal segmental structure and a 'weak grammar', and, it is suggested, with knowledge claims that tend to be legitimated by social rather than epistemic relations. In this particular case study, the horizontal, segmental structure of the discipline was seen to be reflected in a curriculum that currently lacks coherence and cohesion.
\end{abstract}

\section{Introduction}

Barnett (in this issue) begins to explore 'the links between knowledge and student being and becoming'. He brings attention to bear on student agency and the ontological relations involved in learning. He enquires about the personal dispositions and qualities that may be developed in the process of coming to know, suggesting that acquiring such virtues is critical for living in a supercomplex world. In the terms of the Bernsteinian framework adopted in this article, Barnett focuses on the potential for personal development of the regulative dimension of pedagogic discourse: that is, on the moral and social order that is implicated in taking up the subject positions offered to students by various disciplinary curricula. Barnett reminds us of the importance of the 'regulative discourse', and of the potentially positive values and 'epistemic virtues' that may be acquired through mastering a demanding higher education curriculum.

This article does not respond directly to Barnett's, but may be viewed as complementary to his angle. Whilst Barnett focuses on the ontological implications of acquiring the 'rules of recognition and realisation' by the agents of learning in Bernstein's field of reproduction (where pedagogy takes place), this article takes a step back and investigates the epistemic and social relations that structure a curriculum in the field of recontextualisation - before students get to engage with it. In other words, this article looks at what society offers students, what subject positions it constructs for them, as an effect of the structure of the knowledge form involved and of the social context in which that knowledge gets turned into a curriculum. This article could be viewed as filling in a missing link in the long chain of causal inference between a particular form of knowledge, in the field of production, and the specialised consciousness that a particular student may develop, as an effect of engaging with curriculum knowledge at the level of the classroom. 
This article reports on one case study, part of a larger research project, that aims to take up the challenge of Bernsteinian scholars to develop a methodology for characterising different types of curriculum knowledge. The challenge is to view curriculum knowledge both as object and product (derived from a particular knowledge structure and object of study), and as subjective practice (the recontextualisation of disciplinary knowledge into a curriculum, informed by social interests and relations). Rather than exploring the role of students as agents of learning and the ontological implications of their knowing, this article explores the role of academics as agents of recontextualisation in order to understand the nature of the curriculum that society structures for students before they get to act on it.

Two research questions are addressed: firstly, at a theoretical level, the relationship between knowledge structure and curriculum structure. Sociologists of education have already put this question on the research agenda. Maton (2000) states that one cannot read off curriculum structure directly from knowledge structure, and that this relationship remains an area for further exploration. Because knowledge structures tend to remain implicit to those working in the field of production, they usually only become visible and explicit as deliberate attempts are made to reveal them when the knowledge gets recontextualised into a curriculum. However, Bernstein's (2000) insight that a ‘discursive gap’ always occurs when a discourse is relocated from its original context of production, alerts one that there will not be a direct translation of knowledge structure from the field of production to the field of recontextualisation. Furthermore, in his work on the 'epistemic device', Maton (2007) claims that, for every knowledge structure, there is also a knower structure. If this is the case, then any analysis of curriculum knowledge needs to take into account its knowledge structure, its knower structure and the social and cultural structures of its recontextualising context.

At the empirical level, the second research question, 'what drives and legitimates the curriculum in one sociology department?', was pursued to shed some light on the theoretical question posed. The empirical question was addressed more specifically by asking:

(a) How has knowledge in sociology in South Africa been classified and legitimated over time, how has it changed and what are the current debates and contestations around knowledge in this particular department?

(b) What recontextualising rules are at work in curriculum development in this particular institutional context? What internal, necessary constraints and enablements are imposed on the curriculum by the structure of the knowledge and its object(s) of study, and what external (arbitrary or contingent) factors relating to context and social relations in the field also shape this curriculum?

This case study of one sociology department in a research-led university was conducted during the departmental deliberations on curriculum restructuring that occurred in the wake of a departmental review, conducted in September 2007. These deliberations were conducted in an institutional context where academics who teach non-professional programmes still enjoy high levels of autonomy with regard to curriculum development. A definitive answer to the theoretical question will not be obtained on the basis of this one case study alone. It is hoped that in time it will be possible to compare findings across a range of disciplines and programmes, using a similar methodology, in order to come to some more general conclusions. 
What is important at this early stage is to develop a rigorous, operationally feasible, methodology for researching curriculum and knowledge based on the rich conceptual framework provided by realist sociologists of education in the Bernsteinian school. Whilst Bernstein's work has had some impact on researching schooling, it is surprising how little empirical work has been undertaken to apply his work to higher education.

In post-apartheid South Africa, the new democratic government has tried to harness higher education to serve the needs of the state more explicitly, through policy injunctions to higher education to become more efficient, relevant and socially responsive, and to produce more South African black graduates (Department of Education 1997, 2001). Despite greater state control in many other areas of higher education to realise this 'transformation imperative', and apart from professional requirements, the curriculum has remained largely a sacred academic space and responsibility. Thus, in this article, academics are positioned as the key recontextualising agents of the curriculum.

\section{A conceptual framework for analysing knowledge and curriculum}

The conceptual framework for this research project uses Bernstein's key concepts: classification, framing and those contained in his theorisation of the pedagogic device. The pedagogic device comprises three fields of activity: the field of production (research), the field of recontextualisation (curriculum development) and the field of reproduction (teaching practice). Central to this study is Bernstein's (1990, 2000) concept of pedagogic discourse (curriculum knowledge and practice produced in the field of recontextualisation). For Bernstein, pedagogic discourse comprises two analytically distinct elements, an instructional discourse (that carries specialised content and skills) and a regulative discourse (that creates the social and moral order of the curriculum). Bernstein argued that pedagogic discourse has its own logic that is different to that of the knowledge discourses produced in the field of production: 'Pedagogic discourse is constructed by a recontextualising principle which selectively appropriates, relocates, refocuses and relates other discourses to constitute its own order' (2000, 33). This is due to a 'discursive gap', that always occurs when knowledge is relocated from the field of production to the field of recontextualisation. According to Bernstein, this 'discursive gap' provides a space for ideology to play that is usually filled by the curriculum developer's ideas around the purpose of education, the ideal moral and social order, staged notions of an ideal learner or graduate, and notions of how learning occurs. These historically and culturally arbitrary ideas, termed by Bernstein the 'recontextualising rules', shape how knowledge discourses reappear in the curriculum and how pedagogic subjects (students) are constituted. This is done by the selection of content, its sequencing, pacing and the establishment of evaluative criteria for judging the production of legitimate texts by pedagogic subjects.

In his later work Bernstein looked at 'relations within' knowledge, and aimed to make knowledge visible as an object by describing different knowledge structures. 
Maton (2000, 2006, 2007) and Moore and Maton (2001) have extended Bernstein's work on knowledge structures through the concepts of the 'epistemic device' and 'legitimation codes'. Maton (2007) asserts that for every knowledge structure there is a knower structure, thus holding together the objective and subjective dimensions of knowledge. Moore and Maton, focusing on the field of production, try to understand the mode of production of knowledge by analysing the 'generative principles' that produce the knowledge structures described by Bernstein. They do this by looking at how knowledge claims come to be viewed as legitimate on the basis of two analytically distinct relations:

(a) The epistemic relation (ER) that generates a knowledge structure - the relation between a knowledge claim and its object of study (this is a non-arbitrary, necessary relation intrinsic to the knowledge itself).

(b) The social relation (SR) that generates a knower structure - the relation between the knowledge claim and the subject or knower (this is an arbitrary relation based on power relations and contextual contingencies).

According to Maton (2000, 2006, 2007), it is the relative settings of these two relations (and the strength of their classification and framing $\mathrm{ER}+/-, \mathrm{SR}+/-$ ) that determines the legitimation code of a particular knowledge form - at any of the three fields of the pedagogic device. Moore and Maton claim that control of the epistemic device is the means whereby intellectual and educational fields are maintained, reproduced and changed.

Maton's (2006, 2007) later work on legitimation code theory lends itself to empirical application as it is relatively simple to operationalise. In this particular study, academics were interviewed in order to interrogate the basis of their claims for the legitimation of their disciplinary and curriculum knowledge and expertise. Maton's two relations (ER and SR) were used to code the interview data. If claims about knowledge are justified on the basis of the possession of specialised knowledge, skills and procedures, then 'knowledge code' (ER+, SR-) is assumed. If knowledge claims are justified on the basis of the possession of specialised dispositions, attributes and social location, then 'knower code' (ER-, SR+) is assumed.

Maton (2007) claims that the humanities and sciences have contrasting legitimation codes: in science the hierarchical principle (by means of which knowledge is specialised and progresses) lies in its knowledge structure (ER+), as in Bernstein's metaphor of an integrating triangle, while its knower structure tends to be flat and democratic (SR-). In other words, it doesn't matter who you are in the science disciplines, provided you possess the correct knowledge and can carry out the required procedures and methods. By way of contrast, at least historically in the humanities, the hierarchical principle lies in the knower structure $(\mathrm{SR}+)$, which tends to remain implicit, while its knowledge structure is less vertical and less clearly bounded (ER-). In other words, while the knowledge forms are more contested and open-ended in the humanities, who you are and the social and cultural capital that you bring to your knowing is what counts (but this often remains implicit).

Sociology was described by Bourdieu as an undisciplined discipline (Vitale 2001), and by Bernstein (1999) as an example of a horizontal knowledge structure that is serially and segmentally organised, with strong insulation between non-comparable discourses (a 'collection code' structure), with a weak grammar of realisation and limited scope for progression. 
Vitale (2001) used a Bernsteinian framework to analyse sociology as taught in European universities in the 1990s. Rather dramatically, he concludes that sociology is marked by 'relativism' and 'semantic anarchy', because it is comprised of a plurality of sub-disciplines and competing specialisations. Vitale also suggests that that there are different 'national styles' of doing sociology (134-6). These characterisations of the discipline were tested empirically in the case study, as was the expectation that sociology's knowledge structure would generate a predominantly knower legitimation code (SR+, ER-). The implications of this type of knowledge structure for curriculum were also explored.

\section{A methodology for analysing knowledge and curriculum}

The theoretical framework outlined above was adopted to analyse curriculum knowledge because of its ability to objectify knowledge, enable theoretical progression and to offer concepts that lend themselves to concrete operationalisation - for example by analysing the classification and framing values of curriculum texts. Curriculum documentation for the case study was initially gathered from the department's self-review portfolio, generated for the purposes of a departmental review. The review was followed by a departmental workshop to discuss curriculum and staffing issues. The researcher obtained permission from the head of department to attend this workshop, and to take field notes. At the beginning of the workshop the researcher presented a research proposal to all members of the department. After some discussion around reservations by some on the issue of anonymity, permission was granted to the researcher and her assistant to conduct this study. Additional data was gathered via in-depth interviews with staff, and an electronic questionnaire sent to a purposive sample of postgraduate students. Interviews were requested with all members of staff in the department. Nine out of twelve responded, and one later withdrew. The interviews were conducted by the researcher and the research assistant, and transcribed by the latter. Transcriptions were returned to interviewees for checking.

The three fields of Bernstein's pedagogic device were used to structure the study (work on the field of reproduction is still in progress and is not reported on here). In the field of production, the research question asked was 'how has knowledge in sociology in South Africa been classified and legitimated over time, how has it changed, and what are the current debates and contestations around knowledge in this particular sociology department?' For the field of production, interview data was coded using the following categories: canon debates, shifts in content and object of study, shifts in theory and method, boundaries within sociology and between sociology and other categories, and the nature of sociological expertise. The concept of classification was used to indicate the degree of insulation and, therefore, the degree of specialisation, and the strength of the power relations retaining these boundaries, within and between sociological knowledge and other categories of knowledge. Additional data sources drawn on here included a limited literature review on the debate around a sociological canon and the history of sociology in South Africa. 
In the field of recontextualisation the research question posed was 'what recontextualising rules are at work in curriculum development in this particular context; what internal, necessary constraints and enablements are imposed by the structure of the knowledge and its object(s) of study; and what external, arbitrary or contingent factors related to context and social relations in the field also shape the curriculum?' Data sources included curriculum documentation, interview data coded according to the categories of institutional culture, departmental culture, current drivers of curriculum change, and academics' criteria for the selection of curriculum knowledge. In addition a questionnaire was sent out on email to all postgraduate students who had completed the undergraduate sociology major $(n=11)$, to probe their experience of the undergraduate sociology major. Six students responded. Provisional conclusions about the nature of the curriculum were tested against postgraduate students' opinions. Maton's concepts of epistemic and social relations were used to analyse the interview data in order to indicate how different sociologists legitimated their selection of curriculum knowledge.

\section{Findings in the field of production}

\section{The nature of sociology as a discipline}

In the literature and interview data, there was some debate as to sociology's status as a discipline, and whether or not it has a canon. Jubber provides a secular definition of canon as the 'body of texts and rules that serve to establish and define a particular discipline and set of practices' (2006, 323). He explains how 'sacred' texts themselves become the rules or criteria for judging future texts. Although sociology may have experienced a few 'canonical moments', these have not been sustained, thus Jubber claims that it never has, and is unlikely in the future, to achieve the status of a canonical discipline (see also Vitale 2001). Jubber argues that instead of a canon, sociology has developed an array of 'compilations' that allow for a certain amount of arbitrariness, plurality and contestation of content. Sociology's lack of canonicity, its permeable external boundaries, and tendency to add on new segments rather than build vertically, appears to be borne out by a cursory glance at the programme for the XVI World Congress of Sociology (July 2006), which accommodated 53 different research committees covering a diverse range of research areas.

Jubber explains sociology's failure to develop a canon in terms of its teleological and epistemological uncertainty. It is 'impossible to unambiguously specify what the nature and purpose of the discipline is', and sociology is 'unable to clearly specify what work qualifies as sociology and who is qualified to be viewed as a sociologist' (2006, 321). Several sociologists in the department supported this view, one claiming that 'sociology lurches from fashion to fashion', 'driven by questions and issues raised by society at large' that 'displace our agenda'; 'the people in this phase may well be obliterated by the next one' (R 2).

Jubber argues that because sociology 'suffers from epistemic weakness' $(2006,328)$ it cannot provide the conditions for the emergence of a common canon. Because of its epistemological contestations, 'the prospect of sociology ever being a science and hence forming a disciplinary canon is permanently blocked by the naturalism versus anti- or nonrationalism divide' (2006, 328). 
Jubber's position is close to that of Bernstein (1999), who suggested that sociology's 'horizontal knowledge structure' means that new knowledge creates a new segment, that sits alongside and contests old knowledge, rather than building on it and subsuming it. This concern about 'weak grammar', segmental developments and a lack of progress in the discipline was echoed by a number of the sociologists interviewed; for example:

One of the problems of people ... not having any commitment to the concept of sociology, and having rather mixed commitments to the department of sociology and of people carving out their own niches, 'I am an Xist, not a sociologist' ... the less likely you are to have debate and some kind of progress of knowledge within a department or in a discipline ... And this has enormous problems for curriculum as well. (R 7)

Regarding the boundaries between sociology and other disciplines, Jubber describes sociology as 'a convenient home for scholars from a wide range of disciplines', and 'a womb for the gestation of numerous perspectives, approaches, studies and disciplines' (2006, 321). This point is validated by the heterogeneous academic backgrounds of members of the department - at least half of whom do not have undergraduate degrees in sociology. Most of the sociologists confirmed the view that sociology has permeable, ill-defined (weakly classified) external boundaries, especially with regard to other social sciences: 'I don't think, epistemologically, ontologically, there is anything distinctive about sociology’ (R 7).

Several interviewees expressed ‘status anxiety’ or 'status ambiguity' (Adesina 2006) with respect to their discipline. Some saw sociology's weak epistemic base reflected in its low status in the field of higher education generally, especially in comparison with the sciences: 'I think the social sciences are massively underresourced compared to say engineering or science ... We haven’t yet proved to society that we have something to offer' (R 1).

\section{The historical development of sociology in South Africa}

With regard to the different purposes (teleology) of sociology, Burawoy (2004) conceptualises four types of sociological scholarship: professional, critical (serving an academic audience), policy and public sociology (serving an extra-academic audience). He argues that, in South Africa, due to its close ties with political agendas (pro- or anti-apartheid), sociology has tended to serve an extra-academic audience. The dominance in South Africa of public and policy sociology, often working off a critical theory base, at the expense of professional sociology is supported by interview data and by Jubber (2007). Jubber's periodisation of the history of sociology in South Africa can be summarised as: 1900-1950s - sociology in the service of poor whites; 1960s-1990s - sociology in the service of either the implementation of apartheid or of the anti-apartheid struggle; post 1994 - pluralism including some policy sociology in the service of the new democratic government, the emergence of new relevant niche areas - some based on post-structuralist or postmodernist theory and the (re)emergence of professional sociology. Interestingly, the interview data suggests that each period was dominated by a different theorist: 1900s-1950s and pro-apartheid sociology by Parson's structural functionalism; 1960s-1994 by Marx's political economy and neo-Marxist revisionist historiography and the post-1994 period by Foucault (if post-structuralist). 
One sociologist spoke about the anti-intellectual shadow and the strong 'knower-code' of the Marxist antiapartheid public sociology of the 1970s-mid-1990s, when '[sociology] became incredibly politicised' and 'people split into ideologised camps' (R 5). Another suggested that the current period is one of re-adjustment and an attempt to find new relevance and identity, especially for those who were anti-apartheid public or policy sociologists during the eighties and nineties: 'The [post-1994] shift was that people ... rediscovered the value of academic research, detached from those political routes and angles’ (R 7). His analysis suggests a contemporary shift to serving an academic audience (a strengthening of the epistemic relation, although, not necessarily a weakening of the social relation). Historically, South African sociology's commitment to serving (certain groups in) society and its focus on public sociology suggests a knower legitimation code, that is, sociological knowledge was legitimated by who was producing it and for whom, rather than by, for example, the rigour of its method. This strongly politicised history of sociology in South Africa has consequences for current debates and curriculum development in this department.

\section{Current contestations around knowledge in one sociology department}

In this section data is drawn from the sociologists' responses to questions asking them to define sociological expertise, and the kind of graduate their curriculum aims to develop. An attempt is made to tease out the ontological, epistemological and teleological implications related to the different legitimation codes adopted within the department.

Some sociologists took up a position that suggested a strongly bounded object of study and specialised procedures to access it, thus demonstrating the ER+ value:

The main aim is to teach students to think about evidence and its relation to theory, how to understand it ... So, it boils down to being able to conceptualise and interpret and develop ideas about how things might be until you get evidence to see how they actually are and to try and do that with a range of methods. (R 2)

This was often linked to a commitment to a realist ontology and the scientific method: 'this whole attack on science and the scientific method ... it's almost a crime against humanity', ‘certain descriptions just won’t last, they will be defeated in time’ (R 5).

Other sociologists took up positions that demonstrate the dominance of the SR+ value (knower code):

One really does need wisdom ... the mind stuff together with the heart stuff ... coming to knowledge from an empathetic position, from an imaginative capacity to understand the people that you are studying and the social conditions that you are studying, at a human level ... You also need a respectful attitude towards difference ... Justice, fairness, a bit of outrage. (R 8) 
With regard to graduates, these sociologists described their ideal graduate in terms of knower attributes. Given this range of positions in the department, and the strongly articulated boundaries between them, it is hardly surprising that differences were expressed between its members. As one interviewee noted, 'I don't think there's too much consensus on what specifically we are trying to produce in the department' (R 3). Overall the data gives a picture of contrasting legitimation codes, suggesting that within this one department fundamental epistemological, ontological and teleological differences are entertained. It is risky to generalise from this very limited sample, but an emergent pattern was evident where those adopting an emancipatory teleology (critical sociologists), and/or a post-structuralist/constructivist epistemology and idealist ontology, tend to subscribe to a knower code of legitimation. On the other hand, those who promote professional sociology tend to adopt a realist ontology, a postpositivist epistemology and subscribe to a knowledge code of legitimation. This may be an overly simplistic dichotomy, and it was not clear from the data that this pattern holds for all the respondents interviewed. Further research would be required to see whether this pattern holds consistently for a wider range of social scientists. The diversity of positions in this department may also be a reflection of the historical period in which it finds itself, where old identities and positions tied to anti-apartheid public sociology are no longer salient, and new 'niche areas' are being pursued in a pluralist, individualistic and competitive institutional environment. It appears that no new departmental or disciplinary leadership has emerged to make an organisational and intellectual centre hold.

\section{Findings in the field of recontextualisation}

The field of recontextualisation is the context in which knowledge gets relocated from the field of knowledge production in order to create a curriculum for students. As described above, the horizontal, segmental structure of sociological knowledge in the field of production may be an effect of its knowledge claims often (but not always) being legitimated on the basis of social rather than epistemic relations. One might hypothesise that the implications of such a knowledge structure for the field of recontextualisation would be that the curriculum is highly contested, because the knowledge structure itself does not provide a strong objective basis for the selection of content, its pacing and sequencing, (as would be the case for a discipline with a more hierarchical knowledge structure). The expectation that the selection of curriculum knowledge in this department would be contested was confirmed in the interview data:

We give them [students] a totally arbitrary and fragmented, bitty kind of education ... it's very unsatisfactory. But then I think there is no satisfactory sociology curriculum, it is impossible to construct it, it's just too vast of a discipline, it's too messy ... We have had many debates over many years about constructing an integrated, coherent, a sequenced, curriculum, but we've never got there. (R 5)

I don't believe there is a unified view in the department, I think different people have completely different concepts [of the curriculum]. (R 1 ) 
The data suggest that this contestation and lack of agreement over curriculum content in the department has led to a lack of coherence and cohesion in the undergraduate general sociology major. This impression was confirmed by postgraduate students who have completed the major. Students complained of 'confusion', 'working in the dark' and a 'vague' overall picture. One student noted, 'I found that each course was more or less its own entity and that no course really built onto another'.

Jubber laments that because 'sociology in South Africa has lacked a clear and defended disciplinary identity and boundaries', its undergraduate curriculum has become 'fragmented, cluttered and superficial' (2006, 333). He explains the challenge for curriculum development thus:

In the case of sociology there are not only challenging differences in epistemology, ontology, methodology, concepts and theory to be dealt with, but most significant, the object of study, if this is taken as local society, is different for each community of sociologists. $(2006,334)$

This is an important move, also supported by Vitale (2001), which suggests that sociology's horizontal knowledge structure and weak grammar may, in part, be attributed to it having an indeterminate, context-specific object of study. In certain contexts, this may permit the social relation to dominate the construction of the curriculum. This suggests that disciplines such as sociology, with horizontal knowledge structures, may be more vulnerable to calls from nonacademic stakeholders, to offer curricula that are 'relevant' and 'responsive' to the needs of society, than those disciplines with hierarchical knowledge structures. In this regard, Jubber (2006) suggests that the 'curriculum disarray' in South African universities is a legacy of the historical over-commitment to public sociology in South Africa. One respondent suggested that this responsiveness to society in the sociology curriculum continues in the present:

I think most of our courses are in part responsive to social issues, it's always been done ... I think subjects have changed and debates have changed, but it's still highly responsive to what's going on ... I think every course you look at, it is in some way responding to issues in post-apartheid society.

There was also evidence that the differences around knowledge affect the departmental culture negatively, and make communication and organisational cohesion difficult. In this sense, the social relations of the immediate organisational context have an effect on the recontextualising rules for curriculum construction:

I think there is very little coordination, very few people know much about what is being taught in the other people's courses, because people mind their own business ... people teach what they want to teach ... On the pedagogical side, I think that there probably ends up being some logic despite the lack of coordination, but on the content side, the substantive knowledge side, I think that it's a complete anarchic mess, it’s a real problem. (R 7)

The data suggests that these different epistemological and ontological positions come to define academic identities and life-worlds, and so seep into departmental politics and culture. Many interviewees tended to identify more strongly with specific sub-disciplines or niche areas than with the discipline itself: 
'I see myself as another sub discipline' (R 4), 'I've become part of a sub-grouping or a subfield that is fairly developed globally' (R 8).

When I came here I made it clear to them that I had some expertise on issues that were not offered in the department, and I was not prepared to change and do what the department was doing just for a job at X ... Almost all the courses I was given, I changed to reflect my own interests, my own orientation, and my own experiences ... If I was forced to teach something that I'm not interested in, that I am not researching, I would probably leave. (R 6)

In this particular department, the segmental structure of sociological knowledge, the differences around epistemology and the lack of a strong social or intellectual principle of cohesion, means that academics are left to teach to their particular specialisations and niche areas, and design the curriculum accordingly:

You know, to a hell of a large extent, it depends on who's there ... it's more a question of, 'let's see who we get and then see what knowledge we can construct around them'! (R 8)

The dominance of this 'knower code' in the curriculum was confirmed by postgraduate students in response to the question, 'what did your lecturers value when they marked your work?': 'I had no idea what they valued or what they were looking for when marking', 'each lecturer looks for different things', 'sociology lecturers, only teach their niche ... you could score some easy marks by telling them what they want to hear', 'they valued arguments in line with their opinions'.

In the interview data, respondents also mentioned other external factors that shape this sociology curriculum. These were often perceived negatively, and arise from the wider institutional context and culture. The following contextually contingent factors were mentioned: the imminent retirement of key staff members; the recent imposition of a managerial culture that has destroyed collegialism and caused a culture of competition rather than cooperation to develop between academics; competition for resources between departments, linked to competition for students numbers in the social sciences; the advent of programmes that were initially independent from and undermined departmental and disciplinary structures; the need to make the staffing of the programmes more sustainable; and the need to attract and retain more postgraduate students in the department.

Of course, there are other structures in a university context that shape the university curriculum, but that are so taken-for-granted that they did not even surface in the interviews. For example, the university timetabling, calendar and venue arrangements assume a curriculum structure that is based on disciplines, that strongly classifies categories of knowledge (a collection code curriculum), and strongly frames pacing and hierarchical rules between subjects. These institutional 'regulative rules' serve to counter the weakening of framing that would otherwise occur on the more responsive and creative boundaries of this department's curriculum. 


\section{Discussion}

The analysis of the data gathered for this study suggests that there may be a necessary relationship between the object of study and the form of knowledge that can be produced about that object. But, as with any social practice, structure, in this case knowledge structure, can only provide enablements and constraints within which agents (academics as recontextualising agents) must work. As implied in Bernstein's concept of the 'discursive gap', the shift from knowledge in the field of production to curriculum knowledge in the field of recontextualisation entails a process of translation that is socially determined. Increasingly in higher education, extrinsic pressures from the state and the market, often filtered down as requirements by institutional management, become arbitrary 'rules' that seek to regulate the recontextualisation of knowledge into curriculum.

However, given that the heartland of curriculum design remains the preserve of academics, especially in non-professional programmes and majors, it is the interests, concerns and projects of the individual recontextualising agents that meditate between knowledge structure and other structures in the construction of curriculum and pedagogic practice - shaping it in very contextspecific and personal ways. What is particularly interesting about these findings is how closely the identities of the academics who participated in this study are related to their positions on knowledge, and how much scope this particular institutional and organisational context allows these identities to shape the curriculum.

Given that sociological knowledge has a horizontal, segmented structure that entertains a series of teleological, epistemological and ontological positions - including the great divide between post-positivism/realism and post-structuralism/idealism - it is hardly surprising that in the individualistic, laissez faire culture of this recontextualising field there is trouble around the selection of curriculum knowledge. In this particular case study, the knowledge structure of the discipline combined with this particular departmental culture allows knower allegiances, interests and identities to 'play' in the discursive gap, constructing units of curriculum that are in keeping with the positions, specialisations and identities of individual academics. During the general sociology major, students are exposed to a series of non-commensurable pedagogic discourses, with no overall coherence provided, even by a unifying dominant regulative discourse. It appears that the excellent curriculum development work that some academics put into their own courses is undermined by the incoherence of the major as a whole. This incoherence is exacerbated by the contestations around that knowledge that exist within the department. It is little wonder that even strong undergraduate students find themselves 'confused', 'in the dark', feeling 'vague' and not always sure of the evaluative rules.

\section{Conclusion}

With regard to the theoretical question posed, 'what is the relation between knowledge structure and curriculum?', the findings of this case study suggest that the form of the knowledge structure in the field of production does impose a set of enablements and constraints, within which the recontextualising agents of the curriculum must work. However, the 'discursive gap' between the two fields allows numerous other contingent factors to play within these constraints and possibilities. Further theoretical and empirical work is required to answer this question satisfactorily. 
Regarding the empirical question posed, the findings of the study suggest that sociological knowledge in South Africa has become more fragmented over time, especially since the great divide in the social sciences between post-positivist and post-structuralist epistemologies, underpinned by realist and idealist ontologies respectively. Furthermore, given its historical commitment to social relevance and political engagement (the dominance of public sociology), sociology in South Africa has been driven predominantly by a knower legitimation code that was particularly strong in this department during the anti-apartheid era. Since then, the performative demands of institutional managerialism imposed in the 1990s have forced sociologists to focus on specialising and publishing rather than teaching. The current situation in this particular department with regard to the sociology major appears to be one of pluralism and difference - with non-commensurable, disconnected courses being offered - resulting in an incoherent pedagogic discourse for the major as a whole. However, what is encouraging in this study is the high degree of self-awareness, and honest and accurate diagnosis of the department's problems in relation to its curriculum, on the part of academic staff.

In terms of a practical solution to the curriculum dilemma faced by the department, it seems there are at least two possibilities. One is to acknowledge the deep epistemic divides in the department, and to give up on a general sociology major and postgraduate programme; encouraging instead the consolidation of at least two specialised undergraduate parallel streams with different underpinning epistemologies - one on industrial and development sociology and the other on inequality, race, class and identity - leading to a range of discrete niche area postgraduate programmes. The second possibility is to forge a collective pedagogic discourse for the general major. This could be based on an explicit meta-language about knowledge, that locates for students the different positions represented in the department, as they move from one course to the next. For this to be feasible, there would need to be strong departmental and intellectual leadership, a collective acceptance of epistemic pluralism, and of the need to explicate for students the contestations around knowledge, plus time and energy to spend on curriculum development. A meta-language about knowledge could become the framework that carries the different contents and positions of the courses and lecturers in the general major, and in the recently proposed general honours course.

The case study suggests that developing curricula from horizontal knowledge structures with weak grammars grants great freedom, but also places a heavy responsibility on the recontextualising agents.

\section{Acknowledgment}

I am indebted to Haley McEwen who worked as research assistant on this project and competently assisted me with the collection and processing of interview and questionnaire data. 


\section{References}

Adesina, J. 2006. Sociology beyond despair: Recovery of nerve, endogeneity, and epistemic intervention. South African Review of Sociology 37, no. 2: 241-59. Bernstein, B. 1990. The structuring of pedagogic discourse. Vol. IV. London: Routledge. Bernstein, B. 1999. Vertical and horizontal discourse: An essay. British Journal of Sociology

of Education 20, no. 2: 157-73. Bernstein, B. 2000. Pedagogy, symbolic control and identity: Theory, research, critique. Revised ed. Lanham: Rowman \& Littlefield. Burawoy, M. 2004. Public sociology: South African dilemmas in a global context. Society in Transition 35, no. 1: 11-26. Department of Education. 1997. Education White Paper 3: A programme for the transformation of higher education. Pretoria: Department of Education. Department of Education. 2001. National plan for higher education. Pretoria: Department of Education.

Jubber, K. 2006. Reflections on canons, compilations, catalogues and curricula in relation to sociology and sociology in South Africa. South African Review of Sociology 37, no. 2: 321-42. Jubber, K. 2007. Sociology in South Africa. International Sociology 22, no. 5: 529-48. Maton, K. 2000. Languages of legitimation: The structuring significance for intellectual fields of strategic knowledge claims. British Journal of Sociology of Education 21, no. 2: 147-67. Maton, K. 2006. On knowledge structures and knower structures. In Knowledge, power and educational reform: Applying the sociology of Basil Bernstein, ed. R. Moore, M. Arnot,

J. Beck, and H. Daniels, 44-59. London: Routledge. Maton, K. 2007. Knowledge-knower structures in intellectual and educational fields. In

Language, knowledge and pedagogy: Functional linguistic and sociological perspectives, ed. F. Christie and J.R. Martin, 87-108. London: Continuum.

Moore, R., and K. Maton. 2001. Founding the sociology of knowledge: Basil Bernstein, intellectual fields, and the epistemic device. In Towards a sociology of pedagogy: The contribution of Basil Bernstein to research, ed. A. Morais, I. Neves, B. Davies, and H. Daniels, 153-82. New York: Peter Lang.

Vitale, P. 2001. The teaching of sociology: Towards a European comparison of curricula. In Towards a sociology of pedagogy: The contribution of Basil Bernstein to research, ed.

A. Morais, I. Neves, B. Davies, and H. Daniels, 129-41. New York: Peter Lang. 